\title{
EFFECT OF FORGING RATIO ON MICROSTRUCTURE AND GRAIN SIZE OF THE STRUCTURAL STEEL USED FOR SPECIAL APPLICATIONS
}

\author{
${ }^{1}$ Ladislav KANDER, ${ }^{2}$ Miroslav GREGER \\ ${ }^{1}$ Material and Metallurgical Research Ltd., Ostrava, Czech Republic, EU, ladislav.kander@mmv.cz \\ ${ }^{2}$ VSB -Technical University of Ostrava, Ostrava, Czech Republic, EU, \\ greger.miroslav@vsb.cz
}

https://doi.org/10.37904/metal.2019.830

\begin{abstract}
This article deals with evaluation of effect of forging ration on microstructural characteristics of structural steel used for special application such as connecting rods, bolts, arbors, pins, axle arm. Intensity of structural changes during forging is usually determined in dependence on the forging ratio. Forging ratio at elongation is most often calculated with use of simple relations, which are based on the change of cross section of the forged pieces. The intensity of structure development is influenced not only by the simple change of cross sections, but also by relative length of the stroke, magnitude of deformation in individual passes, manner of edging, temperature, friction and shape of anvils. The article gives an analysis of influence of the relative length of the stroke on the forging ratio. Comparison of grain size and mechanical properties on applied forging ration is presented in the article.
\end{abstract}

Keywords: Open die forging, forging reduction, relative drawing out

\section{INTRODUCTION}

The quality of large forgings is influenced not only by metallurgical factors of forging, such as the use of ingot, heating, forming temperatures, forging ratio etc., but also by technological factors, which are not only significant in their impact on the quality of forgings, but mainly on economical issues. Especially in the case of forgings with complicated shape it is important to determine the optimal technological principles for their production, so that the required shape of the forged piece is achieved together with a good quality, optimal consumption of metal and at economic production costs.

In many cases of forgings with complicated shape it is more convenient to manufacture a forged piece with technological material allowance with larger metal consumption and lower processing costs, rather than laboriously manufacture forged piece with complicated shape accompanied by large capacity loss of the forging shop and by high production costs.

So far published guidelines for the optimal shape range for production of large forgings are very limited and they do not provide the necessary picture of the optimal shape of the forged piece. Usually, production possibilities of forging are then often overestimated and production costs are higher than in the case of forged piece with simpler shape beeing manufactured with technological material allowance [1,2].

The following technological principles are an attempt to express mathematically the major factors, according to which it is appropriate to carry out production of open-die forged pieces. Majority of those principles were prepared on the basis of operational experience of Czech forging shops and also of international literary references.

Mathematical expression of technological principles is based especially on empirical experience of forging shops and it therefore makes no demands to the exactness of expression. Each of the presented principles would require for exact expression a deeper theoretical analysis and particularly numerous industrial measurements and model experiments and mathematical simulations [3]. 


\section{SHAPE OF ANVILS}

The anvils used at forging can be basically divided into three types: straight, angular and shaped. In the manufacture of large forged pieces by direct elongation of the ingot it is the most convenient to use straight anvils, while the elongation should be performed by re-forging of the multi-edge ingot into an octagonal forged piece followed by gradual change of its shape into the square [4]. Forging of circular forged pieces with crosssections by direct elongation from the ingot should also be performed by re-forging of the ingot into a square forged piece followed by its final shaping into a circular cross-section [5]. This last operation, i.e. the change of the square cross-section into a circular one, should be performed with a minimum elongation.

At forging of circular cross section forgings it is not appropriate to use only straight anvils, since tensile stresses are formed in the central part of the forged piece, which may contribute to crack formation. When docking the circular cross sections, it is advantageous, especially in steels with low formability, to use angular or shaped anvils. For steels less susceptible to cracking it is possible to use a combination of anvils in such a way that the upper anvil is straight, the bottom is angular or shaped. This combination of anvils is most commonly used in forging shops when forging circular rods from large ingots [6].

The shape of anvils affects the uniformity of deformation in cross-section of the re-forged blank. Longitudinal deformation at cross section of the forged piece is significantly uneven when straight anvils are used, while it is much more uniform when angular anvils are used. The optimum forming procedure takes place under conditions when the maximal deformation in the forged piece axis is located and there are no cracks formed on its surface [7]. This condition is best met by angular anvils with the angle of $110^{\circ}$. When shaped anvils are used for forging of circular rods, the ratio of the radius $R_{v}$ to the radius of curvature of the cut-out of the shaped anvil $R_{k o}$ is very important. An ideal situation occurs when $R_{v}=R_{k o}$.

When this condition is met, the contact surface of the anvil with the forged piece is the largest, the spreading is minimal and formation of tensile stresses on the surface and in the axis of the forged piece is restricted [8]. An unfavorable state of stress occurs when $R_{k o}>R_{v}$. The contact surface of the anvil is minimal and forging approaches adverse ratios in forging forged pieces of circular cross sections on straight anvils. That's why it is advisable to select the size of the shaped anvil at the start of forging in such a way that $R_{v} \approx R_{k o}$, and to complete the forging at the ratio $R_{v} \geq R_{k o}$. The largest diameter $D$ of the initial blank that can be forged in angular anvils with the radius equal to the half of curvature $r$ and with the vertex angle $\beta$ is limited by the relation:

$D=2 \sqrt{\frac{S_{k} \cdot K}{\pi}}$

where: $S_{k}$ - the area of the anvil cut-out $(\mathrm{mm}) ; S_{k}=r^{2}\left(2 \operatorname{tg} \frac{\beta}{2}+\pi-\beta\right), K$ - the degree of elongation in one pass; $r$ - the radius of the anvil curvature, $\beta$ - the vertex angle between the tangents to the radius of the cut-out $r$ curvature.

\subsection{Width of anvils, length of stroke and forging ratio}

Used width of anvils at elongation influences the uniformity of deformation, thickness reduction ratio of steel in the forged piece axis and the intensity of elongation. When narrow anvils are used, Figure 1a, although the spreading is small, elongation is effective, but there is the danger of imperfect penetration of deformation in the ingot axis. When very large anvils are used, Figure $\mathbf{1 b}$ (or at elongation with large relative length of the stroke) the penetration of deformation in the forged piece axis is indeed guaranteed, however, in the case of straight anvils the spreading is considerable and intensity of elongation is small. 


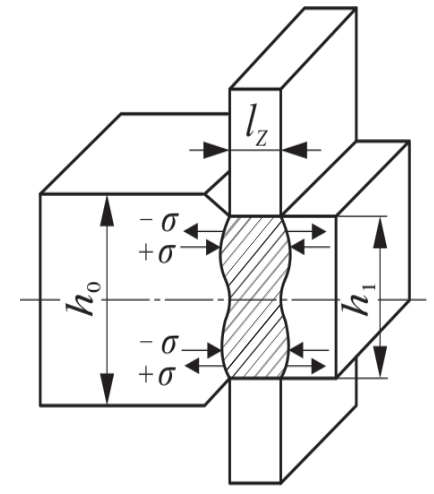

a)

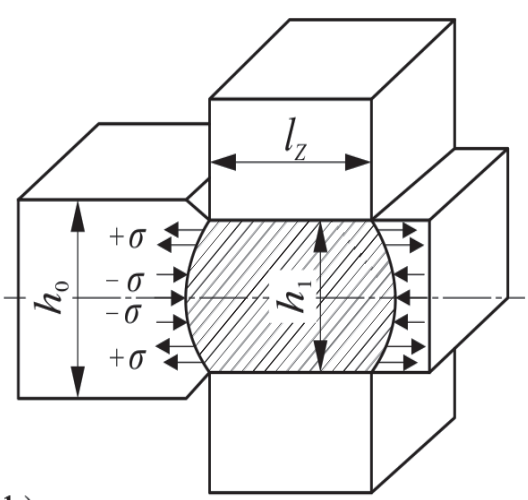

b)

Figure 1 Influence of the width of anvils on thickness reduction ratio of steel in the forged piece axis [8]:

a) shape of the deformation zone at elongation with use of narrow anvils,

b) at elongation with use of broad anvils

It has been proven experimentally that the optimum width of straight anvils should be within the range from 0.5 to 0.7 of the initial height of the forged piece, which can be described by the so-called relative length of the stroke by the relation [9]:

$\frac{l_{z}}{\mathrm{~h}}=0.5-0.7$

where:

$I_{z}$ - the length of stroke $(\mathrm{mm}) ;\left(I_{z} \approx 0.8 \cdot B ; B\right.$ is the anvil width), $h$ - the initial height (or diameter $D$ ) of the forged piece $(\mathrm{mm})$.

At bigger anvil width a considerable unevenness of deformation along the forged piece cross-section takes place, when true strain in the forged piece axis is significantly bigger than the average strain determined by the relation:

$\varepsilon_{h}=\frac{h_{\mathrm{o}}-h_{1}}{\mathrm{~h}_{\mathrm{o}}}$

where:

$h_{0}$ - the height of the forged piece before the deformation $(\mathrm{mm}), h_{1}$ - the height after deformation $(\mathrm{mm})$.

For calculation of the forging ratio by elongation it is possible to use two well-known relations, based on the change of cross-section of the elongated forged piece. The first relation, used most frequently in the forging shops, can be described by the following equation:

$K=\frac{s_{0}}{S_{\mathrm{i}}}=\lambda$

where:

$S_{0}$ - the initial cross-section $\left(\mathrm{mm}^{2}\right), S_{i}$ - the forged piece cross-section after elongation $\left(\mathrm{mm}^{2}\right)$.

In dependence on the magnitude of the applied strain and on the relative length of stroke it is possible to use for determination of the forging ratio by elongation also this relation:

$K=\frac{1}{1-\varepsilon_{h}(1-f)}$

where:

$\varepsilon_{h}$ - the magnitude of deformation, $f$ - the coefficient of spreading at elongation. 
The coefficient of spreading depends on the relative width stroke $I_{z} / b_{i}$ (Figure 2 ). The coefficient of spreading in dependence on the relative stroke when forging on angular anvils with the angle $\beta=120^{\circ}$ is given in the second row, forging on straight anvils it is in the third row of Table 1.

Table 1 Dependence of the coefficient of spreading $f$ on the relative width of stroke $I_{z} / b_{i}$

\begin{tabular}{|c|c|c|c|c|c|c|c|c|c|}
\hline $\boldsymbol{I}_{\boldsymbol{z}} / \boldsymbol{b}_{\boldsymbol{i}}$ & $\mathbf{0 . 3}$ & $\mathbf{0 . 4}$ & $\mathbf{0 . 5}$ & $\mathbf{0 . 6}$ & $\mathbf{0 . 7}$ & $\mathbf{0 . 8}$ & $\mathbf{1 . 0}$ & $\mathbf{1 . 2}$ & $\mathbf{1 . 4}$ \\
\hline $\boldsymbol{f}_{\text {angular }}$ & - & 0.01 & 0.025 & 0.04 & 0.06 & 0.75 & 0.11 & 0.12 & 0.16 \\
\hline $\boldsymbol{f}_{\text {straight }}$ & 0.13 & 0.17 & 0.20 & 0.24 & 0,25 & 0.27 & 0.32 & 0.36 & 0.41 \\
\hline
\end{tabular}

For calculation of relative spreading $\beta^{*}$ at elongation on straight anvils it is possible to use the relation:

$\beta^{*}=\frac{b_{i}-b_{i-1}}{b_{i-1}}=\frac{1}{\lambda\left(1-\varepsilon_{h}\right)}-1$

where:

$b_{i}$ - the blank width in the zone of deformation after applied strain, $b_{i-1}$ - the blank width in the zone of deformation before the applied strain.

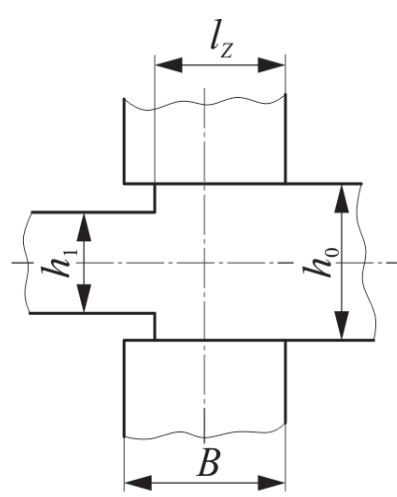

a)

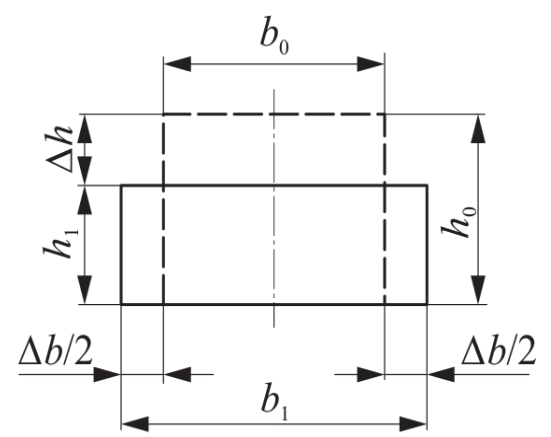

b)

Figure 2 Diagram of the forged piece elongation [8]:

a) anvil width $B$ and length of stroke $I_{z}$, b) change of the cross-section

\section{STRAIN PENETRATION AT ELONGATION}

The relative length of stroke $I_{z} / h_{i}$ affects the depth of strain penetration during elongation. The influence of the relative length of stroke $I_{z} / h$ and the influence of the forging ratio on development of structure in the steel 36 CrNi 6 at elongation on straight anvils was experimentally verified.

The experiments were performed on $15 \mathrm{~kg}$ laboratory ingots. Average dimensions of the ingot cross-section were $90 \mathrm{~mm} \times 90 \mathrm{~mm}$. Chemical composition of the steel is given in Table 2 .

Table 2 Chemical composition of steel $36 \mathrm{NiCr} 6$ (mass. \%)

\begin{tabular}{|c|c|c|c|c|c|c|}
\hline $\mathbf{C}$ & $\mathbf{M n}$ & $\mathbf{S i}$ & $\mathbf{C r}$ & $\mathbf{N i}$ & $\mathbf{V}$ & Al \\
\hline 0.35 & 0.72 & 0.22 & 0.62 & 1.33 & 0.001 & 0.006 \\
\hline
\end{tabular}

The relative length of stroke was approx. 0.6. The forging ratio was determined according to the relation (5) and it was within the interval from 1 to 4 . The forging was carried out in the temperature range from 1050 to $950{ }^{\circ} \mathrm{C}$. The forged pieces were docking annealed at $600^{\circ} \mathrm{C}$ for 2 hours, they were cooled down on air, and samples for metallographic analyses were taken from them [10]. The samples for metallographic analyses 
were taken perpendicularly to the forged pieces longitudinal axis. Due to small size of the experimental forged pieces no analysis of structure size carried along the height of the elongated samples was made. Development of structure in the forged pieces axis in dependence on the forging ratio is shown in Figure 3. Although considerable attention is paid to investigation of the influence of forging ratio on the structure and mechanical properties of forged pieces resulting from it, we currently see and discussing works concerning the influence of the forging ratio on the structure and properties of forged pieces, as well as those concerning the calculation of the forging ratio [8]. All the studies conducted so far clearly evidenced that it is possible to refine the structure by the better (not higher) forging ratio and thus improve also the properties of forged pieces, such as ductility, thinning and notch toughness.

It is evident from Figure 3 that the forged piece structure gets significantly refined from the forging ratio around the value of 6 (Figure 3f), although the forging shops operate mainly with the value of 3 . If an upsetting operation is included into the technology of forging of longitudinal forged pieces, it has been unequivocally proven that the upsetting effect on the development of structure and thus also on enhancement of the mechanical properties is not equivalent to the impact of the thickness reduction ratio achieved by elongation of the forged piece, it means by reduction of the cross-section of the forged piece in respect to the ingot cross section.
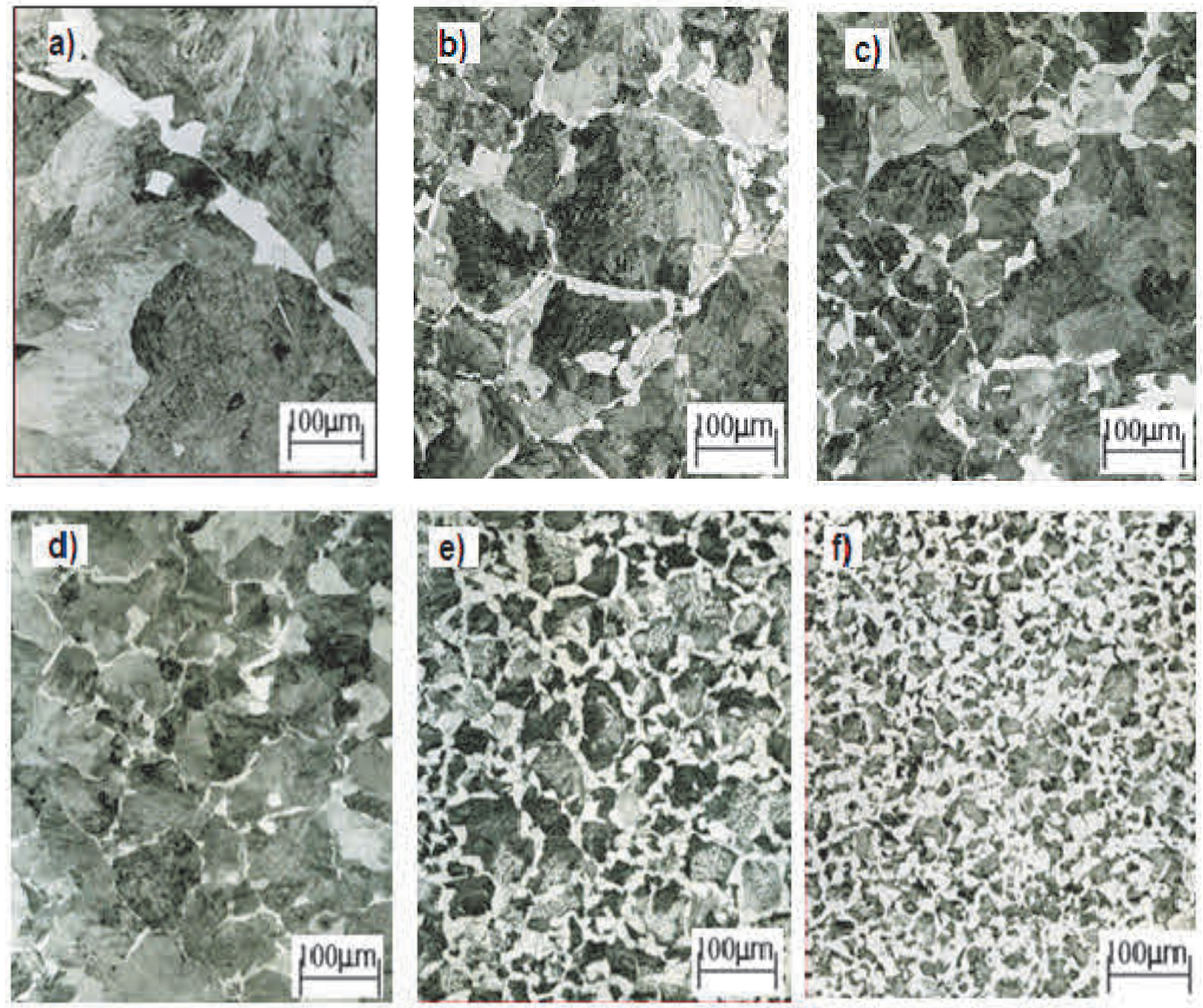

Figure 3 Development of structure of the steel $36 \mathrm{NiCr} 6$ in dependence on the degree of thickness reduction: a) $\mathrm{K}=1$; b) $\mathrm{K}=1.5$; c) $\mathrm{K}=2$; d) $\mathrm{K}=3$; e) $\mathrm{K}=4$; f) $\mathrm{K}=6$ 


\section{CONCLUSIONS}

Due to the fact that for the assessment of production technology the forging shops got used to determination of the forging ratio, while for the pieces forged by elongation the minimum value is set to 3 , it is necessary also for the pieces produced with use of upsetting operation to determine such a calculation of the total degree of forging ratio, which would correctly take into account the effect of upsetting. It is only natural that for determination of this calculation it is necessary to use simplified assumptions, since calculation of the forging ratio gives only an average value due to an unevenness of deformation in the formed forged piece.

\section{ACKNOWLEDGEMENTS}

This paper was created in the frame of the drawing and using institutional support for the long-term and conceptual development of the research organization in 2019. funded by the Ministry of Industry and Trade.

\section{REFERENCES}

[1] TASH, Mahmoud M. Effect of hot forging reduction ratio and heat treatment on hardness, impact toughness and microstructure of carbon and low alloy steels. International Journal of Advanced Technology in Engineering and Science. 2015. vol. 3, no. 3, pp. 57-66.

[2] BABAKHANI, A., KIANI-RASHID, A. and ZIAEI, S. M. The microstructure and mechanical properties of hot forged vanadium microalloyed steel. Materials. 2012. vol. 27, no. 2, pp. 135-139.

[3] ABHAY, V. S, KIRAN, A. and SREEJITH, K. G. The influence of forge reduction ratio on the tensile properties of AISI 321 stainless steel. International Journal of Science, Engineering and Technology Research (IJSETR). 2016. vol. 5, no. 4, pp. 928-931.

[4] MIYAKE, M. and SODANI, Y. Characteristics of austenite grain refinement by high-speed large-reduction forging production technology for fine grained steel by large deformation forging. Materials Transactions. 2014. vol. 55, no. 6, pp. 911-916.

[5] RECKER, D., FRANZKE, M., HIRT, G., RECH, R. and STEINGIESER, K. Grain size prediction during open die forging processes. La Metallurgia Italiana. 2010. no. 9, pp. 29-35.

[6] SHEIKHI, S. Latest developments in the field of open die forging in Germany. Stahl und Eisen. 2009. vol. 129, no. 4, pp. 33-37.

[7] KUKUYRK, B. Optimization of open die forging of big ingots. In Formability '94: The $6^{\text {th }}$ International Conference on Formability. Ostrava: Tanger, 1994. pp. 595-602.

[8] GREGER, M., MADAJ, M., PETRŽELA, J., and LÁSZLO, V. Effect of forging ratio on microstructure of the 1.5710 grade steel. J. Mechanics Engineering and Automation. 2015. no.5, pp. 454-458.

[9] KATO, K., ROWE, G.W., STURGESS, C.E, HARTLEY, P. and PILLINGER, I. Classification of deformation modes and deformation property diagram in open die forging. Journal of the Japanese Society for the Technology of Plasticity. 1987. vol. 28, no. 312, pp. 67-74.

[10] KANDER, L., STEJSKALOVÁ, Š. and ČíŽEK, P. Structure and mechanical properties of austenitic steels affected by sigma-phase precipitation due to exposure to high temperatures. Materials and technology. 2018. vol. 52, no. 5 , pp. 569-574. 